\title{
Response to the Letter to the Editor by the Authors of: Mobile Stroke Units-Cost-Effective or Just an Expensive Hype?
}

\author{
Silke Walter ${ }^{1,2,3,4} \cdot$ Iris Q. Grunwald ${ }^{2,3} \cdot$ Stefan A. Helwig ${ }^{1} \cdot$ Andreas Ragoschke-Schumm $^{1} \cdot$ Michael Kettner $^{5}$. \\ Mathias Fousse ${ }^{1} \cdot$ Martin Lesmeister $^{1} \cdot$ Klaus Fassbender $^{1}$
}

Published online: 25 January 2019

(C) Springer Science+Business Media, LLC, part of Springer Nature 2019

\section{Dear Editor,}

We thank Dr. Cadillac and colleagues for their important comments. The remarks emphasise the lack of information we have in regard to cost efficiency of the use of a Mobile Stroke Unit (MSU) for acute stroke management.

Despite the proven marked time benefit of MSU treatment compared to standard care, even when compared to a highly streamlined in hospital management ("stroke room" concept which comprises of hospital pre-notification, patient handover at the CT scanner to the hospital team, direct imaging analysis, use of point-of care laboratory and start of IV thrombolysis at the scanner table) [1, 2], the cost-effectiveness is still uncertain.

Apart from a lack of prospective studies comparing cost and cost-savings by the MSU approach as compared with standard care, MSUs are currently operating in very different health care systems, different emergency medical services configuration (dispatch alone or in adjunct to the regular first responding team) and different reimbursement models, making it difficult to derive a generalisable answer on cost-effectiveness of this innovation.

As stated by Cadilhac et al., a collaborative approach (such as a dedicated working group for standardisation of economic

This article is part of the Topical Collection on Cardiovascular Disease and Stroke

Klaus Fassbender

Klaus.Fassbender@uks.eu

1 Department of Neurology, Saarland University, 66421 Homburg, Germany

2 Neurocience Unit, Faculty of Medicine, Anglia Ruskin University, Chelmsford, Essex, UK

3 Radiology Department, Southend University Hospital NHS Trust, Southend-on-Sea, Essex, UK

4 The Florey Institute of Neuroscience and Mental Health, The University of Melbourne, Melbourne, Australia

5 Department of Neuroradiology, Saarland University, 66421 Homburg, Germany analysis) could provide the missing information. This could be an aim of the newly formed PRE-hospital Stroke Treatment Organization (PRESTO) that includes groups interested in acute stroke management.

Important information on MSU financial impact can be expected not only by the prospective BEST-MSU trial in the USA, but also from the Melbourne MSU programme.

However, it has to be kept in mind that there are MSUs operating in rural and remote areas. Apart from the difficulty of comparing cost efficiency between urban and non-urban regions, a potentially different pay threshold per qualityadjusted life year has to be considered [3].

\section{Compliance with Ethical Standards}

Conflict of Interest Silke Walter, Iris Q. Grunwald, Stefan A. Helwig, Andreas Ragoschke-Schumm, Michael Kettner, Mathias Fousse, Martin Lesmeister and Klaus Fassbender declare no conflict of interest.

Human and Animal Rights and Informed Consent This article does not contain any studies with human or animal subjects performed by any of the authors.

Publisher's Note Springer Nature remains neutral with regard to jurisdictional claims in published maps and institutional affiliations.

\section{References}

1. Walter S, Kostopoulos P, Haass A, Keller I, Lesmeister M, Schlechtriemen T, et al. Diagnosis and treatment of patients with stroke in a mobile stroke unit versus in hospital: a randomised controlled trial. Lancet Neurol. 2012;11(5):397-404.

2. Ragoschke-Schumm A, Yilmaz U, Kostopoulos P, Lesmeister M, Manitz M, Walter S, et al. "Stroke Room": diagnosis and treatment at a single location for rapid intraarterial stroke treatment. Cerebrovasc Dis. 2015;40(5-6):251-7.

3. Leech AA, Kim DD, Cohen JT, Neumann PJ. Use and misuse of costeffectiveness analysis thresholds in low- and middle-income countries: trends in cost-per-DALY studies. Value Health. 2018;21(7):759-61. 